UDC: 616.718.4-001.5-089.2-77-018.4-092.9

DOI: 10.15587/2519-4798.2021.227854

\title{
CONTROVERSIAL TECHNOLOGIES IN INTRAMEDULLARY OSTEOSYNTHESIS OF RATS FEMUR FRACTURES
}

\author{
A. Mansyrov, V. Lytovchenko, Y. Garyachiy, A. Lytovchenko, O. Miroshnichenko
}

The aim: to conduct a comparative study of osteoreparative regeneration, namely in the periosteal and intermediate areas of the cortex, during intramedullary osteosynthesis of the femur of rats with and without reaming of the bone marrow canal.

Materials and methods. The work is based on the results of an experimental study conducted on 56 white mature laboratory rats, which simulated diaphyseal fracture of the femur and performed stable nail osteosynthesis with reaming of the bone marrow canal in the first series and without reaming in the second series of the experiment. Histological examination of the specimens was performed on the $7^{\text {th }}, 14^{\text {th }}, 28^{\text {th }}$ and $90^{\text {th }}$ day after surgery.

Results. The procedure of reaming the bone marrow canal reduces the potential reparative capacity of bone tissue in the endosteal area and leads to "distorted" activation of the process of the cortex restructuring. There is a significant activation of osteoclastic resorption.

Conclusions. Bone fusion is more active with the use of intramedullary fixator without reaming of the bone marrow canal, because its reaming reduces the manifestations of reparative potentials in the endosteal region and leads to excessive activation of the resorptive process of restructuring the cortex of both endosteal and central part

Keywords: intramedullary osteosynthesis, nail, osteogenesis, reaming, bone marrow canal, osteoblasts, osteoclasts, resorption

How to Cite:

Mansyrov, A., Lytovchenko, V., Garyachiy, Y., Lytovchenko, A., Miroshnichenko, O. (2021). CONTROVERSIAL TECHNOLOGIES IN INTRAMEDULLARY OSTEOSYNTHESIS OF RATS FEMUR FRACTURES, (2 (41)), 4-9. doi: https://doi.org/10.15587/2519-4798.2021.227854

(C) The Author(s) 2021

This is an open access article under the CC BY license (http://creativecommons.org/licenses/by/4.0).

\section{Introduction}

Osteosynthesis of diaphyseal fractures of the bones of the extremities with blocked nails is possible in two ways: with the technology of reamed nail or without reaming (unreamed nail). Clinicians do not point to the convincing advantages of using intramedullary blocked nails with bone marrow reaming technology compared to osteosynthesis without reaming [1]. There are only a few reports in which specialists in trauma surgery indicate a risk of increased bone temperature when reaming the canal to $70{ }^{\circ} \mathrm{C}$, which leads to its necrosis, others note an increase in temperature to only $51.6^{\circ} \mathrm{C}$ and do not state bone necrosis [2]. There is also no convincing evidence of disorders of reparative bone regeneration using two controversial technologies, namely, the likelihood of delayed fusion of bone fragments. Some authors note an increase in the period of consolidation of bone fragments in osteosynthesis without reaming of the bone marrow canal $[3,4]$, while others, on the contrary, note the optimization of reparative osteogenesis without its reaming $[5,6]$. A number of authors point out the expediency of using the technology of reaming the bone marrow canal $[7,8]$, indicating that the bone chips that occur are plastic material.

However, many experts do not see a significant difference between reaming [9] and non-reaming of the bone marrow canal $[10,11]$. To resolve these contradic- tions, we consider it appropriate to conduct further research $[1,12]$.

When fractures heal, three types of regenerates are formed - periosteal, intermedial and endosteal, and the formation of periosteal regenerate is closely dependent on the formation of endosteal regenerate [13]. It is probable that in the conditions of intramedullary osteosynthesis reparative osteogenesis takes place during the formation of two "powerful" types of regenerates - periosteal and intermedial, as evidenced by isolated reports in the literature $[14,15]$. Therefore, the peculiarities of reparative osteogenesis of bone tissue using two different technologies of osteosynthesis of diaphyseal fractures and became the subject of the research.

The aim of the work - to conduct a comparative study of osteoreparative regeneration, namely in the periosteal and intermedial areas of the cortex, during intramedullary osteosynthesis of the femur of rats with reaming of the bone marrow canal and without reaming.

\section{Materials and methods}

To study bone repair, an experiment was performed on 56 white mature (6 months of age, live weight 280-310 g) laboratory rats of the WAG line in the experimental biological clinic of Kharkiv National Medical University from January 2 to March 27, 2019. 
Surgical interventions on animals were performed in aseptic operating room in compliance with all rules of humane treatment of animals, in accordance with EU Directive 2010/63/EU on the protection of animals used for scientific purposes and the minutes of the meeting of the Ethics and Bioethics Commission from October 3, 2018).

The diaphyseal fracture of the rats femur was simulated by osteotomy and stable osteosynthesis was performed with a pin made of certified metal. The study of reparative osteogenesis was performed in 2 series of experiments:

-1 series - stable osteosynthesis with a pin with reaming of the bone marrow canal ( 28 rats -7 rats for each study period).

-2 series - stable osteosynthesis with a pin without reaming of the bone marrow canal ( 28 rats -7 rats for each study period).

Animals were removed from the experiment by quadruple xylazine overdose ( $8 \mathrm{mg} / \mathrm{kg}$ intraperitoneally) on days $7,14,28$, and 90 after surgery.

For histological examination of the reparative process and analysis of the bone outside the fracture area, the femurs of rats (with a regenerated area) were isolated and fixed in a solution with a mass fraction of neutral formalin of $10 \%$ for 2 days. The bones were decalcified in a solution with a mass fraction of nitric acid of $4 \%$ at a temperature of from 18 to $22{ }^{\circ} \mathrm{C}$, after which the clamp was carefully removed. After decalcification, the bones were dehydrated in alcohols of increasing strength $\left(50^{\circ}, 70^{\circ}\right.$ alcohols and twice at $\left.96^{\circ}\right)$ and in alcohol with ether (1:1 solution), enclosed in celloidin. Histological longitudinal central sections (5-7 $\mu \mathrm{m})$ were made on a Reichert sled microtome and stained with haematoxylin and eosin, as well as picrofuxin according to Van Gieson.

\section{Research results}

The study identified the features of reparative osteogenesis of bone tissue in different conditions of intramedullary osteosynthesis of fragments, which are associated with two different surgical technologies for implantation of intramedullary fixator.

Bone tissue in the intermedial fracture zone in animals of the second series appears on the $14^{\text {th }}$ day, in contrast to the first series, where bone tissue in the regenerate was verified only on the $28^{\text {th }}$ day (Fig. 1).

Osteogenic fibroreticular tissue in the intermedial regenerate was represented by fibroblastic diferon cells and osteoblasts arranged in clusters. Osteoblast foci were determined on the territory of the endosteum.

The presence of such foci of osteoblasts, in contrast to the animals of the previous series, may be associated with the proliferation of stromal cells of the bone marrow, the remnants of which were observed in the cerebral canal. In some places in the cortex there were signs of remodelling, which were associated with the presence of dilated bone vascular canals filled with fibroreticular tissue and foci of newly formed bone tissue, as an imprint of local regeneration of microtraumatized bone (Fig. 2).

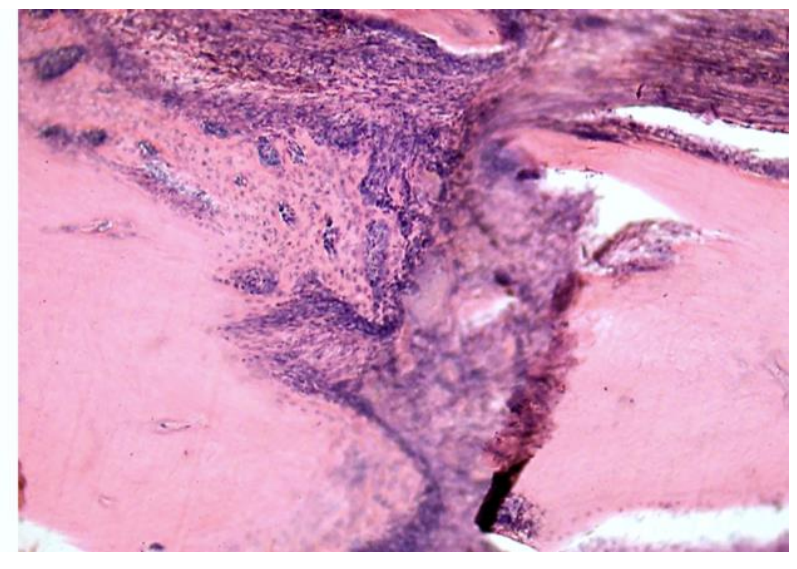

Fig. 1. The interstitial fissure is filled with newly formed bone trabeculae and fibroreticular tissue. 2 series, $14^{\text {th }}$ day. Haematoxylin and eosin, $\times 200$

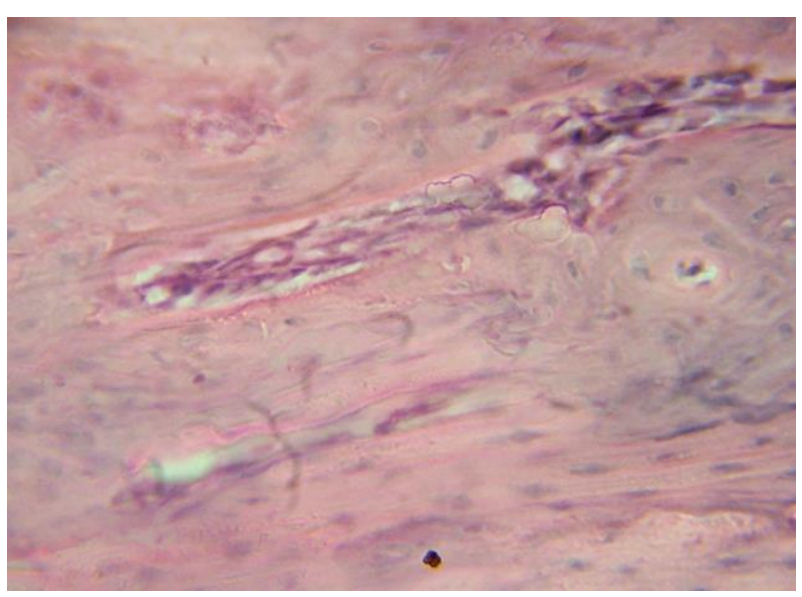

Fig. 2. Dilated bone vascular canal filled with fibroreticular tissue and foci of newly formed bone tissue.

2 series, $14^{\text {th }}$ day. Haematoxylin and eosin, $\times 400$

The morphological picture of bone fragments in the area of osteotomy in animals of the $1^{\text {st }}$ series at this observation period was significantly different. The edges of the bone fragments lost their clarity, osteocytes were not detected in the marginal areas of the fragments. Vascular canals in the bone near the experimental fracture were dilated only in small areas. In some of them, fibroblastic diferon cells and blood vessels were located.

Remains of a blood clot in the form of fibrin-like masses and narrow layers of granulation tissue were noted along the inner edge of the endosteal cortex (in the bone marrow canal). In the granulation tissue located between the fixator and the endosteal surface of the cortex, mainly fibroblastic diferon cells, thin collagen fibers that formed a disordered network, and single lymphoid cells and macrophages were observed. Osteoclasts with three or four nuclei were found on the endosteal surface of the bone in shallow recesses. The presence of osteoclasts on the surface of the bone indicates the activity of remodelling processes, which run on the type of osteoclastic resorption, which can contribute to the thinning of the cortex (Fig. 3, $a, b$ ). 
On the $28^{\text {th }}$ day in the animals of the $2^{\text {nd }}$ experimental series, the intermedial regenerate, which connected the bone fragments, is represented mainly by a fineloop network of bony trabeculae of lamellar structure (Fig. 4).

In animals of the $1^{\text {st }}$ series in 28 days in the area of osteotomy fibroreticular tissue, chondroid foci, coarsegrained bone trabeculae are found (Fig. 5).
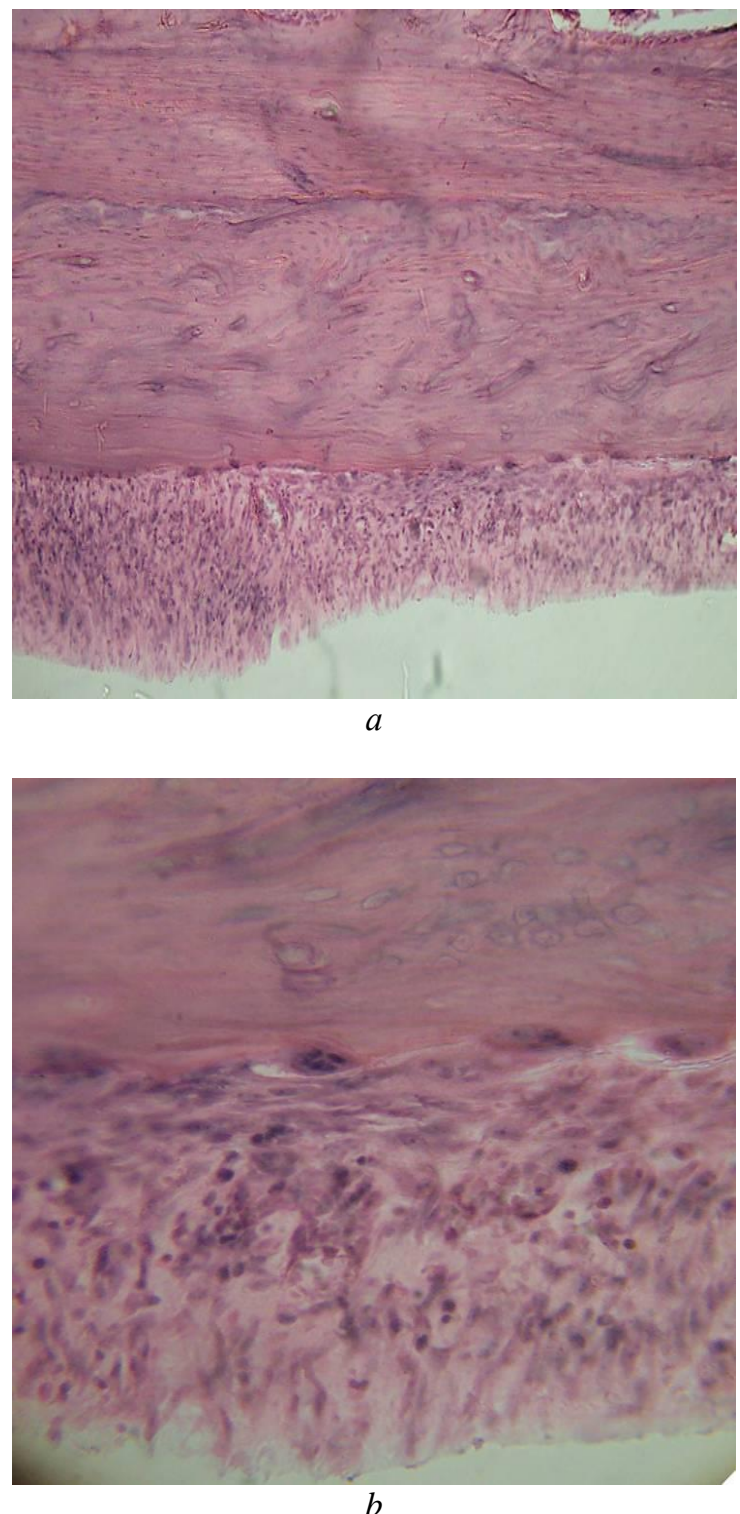

Fig. 3. Osteoclasts on the surface of the endosteal part of the cortex. Empty lacunae of osteocytes. Granulation tissue with a significant density of fibroblastic diferon cells, lymphocytes and macrophages: $a$ - increase $\times 100$; $b$ - increase $\times 400.1$ series, $14^{\text {th }}$ day.

Haematoxylin and eosin

The latter sprouted from the periosteum and formed an intermedial regenerate. The cartilage cells in the chondroid were large with weakly basophilic stained nuclei. The chondroid in the interfragmental area was interspersed with fibroreticular tissue, in which fibroblasts of different maturity located between the bundles of collagen fibers were found. The tight connection of the intermedial regenerate with the maternal bone was observed only in some areas.
The periosteal surface of the cortex in animals of the $2^{\text {nd }}$ series was almost completely rebuilt and was represented by a fibrous layer with thick bundles of collagen fibers with single fibroblasts between them (Fig. 6).

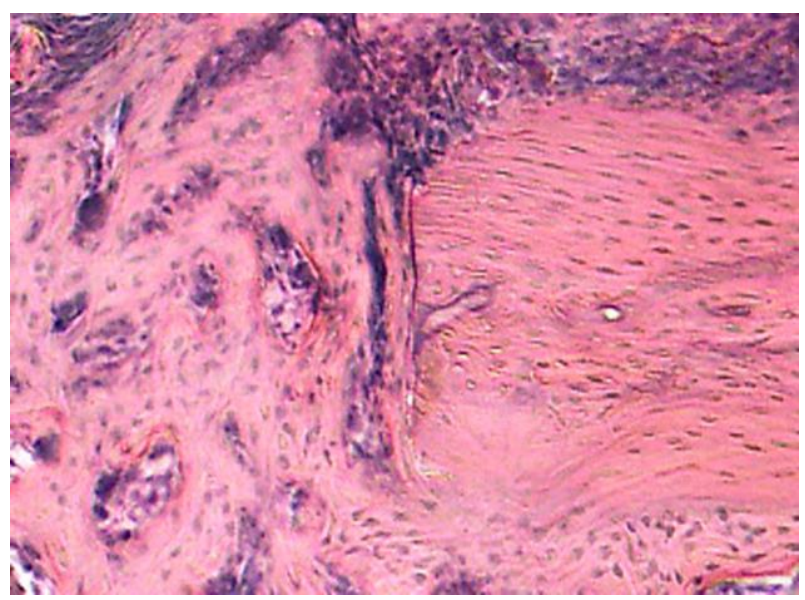

Fig. 4. Fine-loop mesh of bone trabeculae of lamellar structure in the interstitial fissure. 2 series, $28^{\text {th }}$ day. Haematoxylin and eosin, $\times 400$

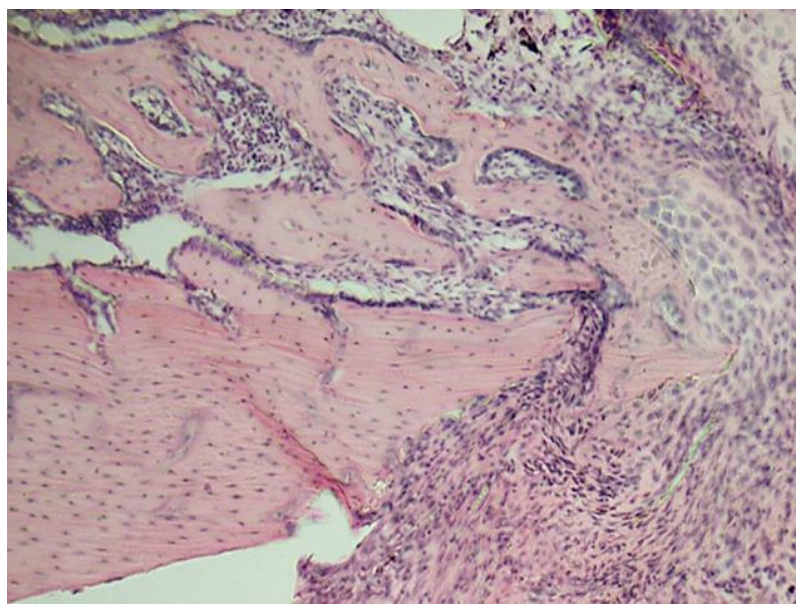

Fig. 5. Large-loop mesh of bone trabeculae in the periosteum. Fibroreticular tissue and areas of chondroid with high cell density. 1 series, $28^{\text {th }}$ day. Haematoxylin and eosin, $\times 200$

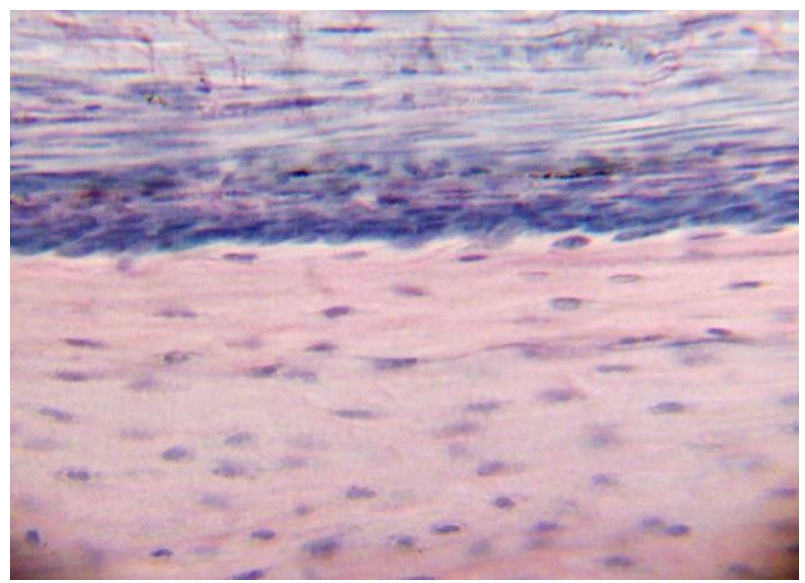

Fig. 6. Thickened periosteum with developed osteoblastic and fibrous layers. 2 series, 90 days. Haematoxylin and eosin, $\times 400$ 
In experimental animals of the $1^{\text {st }}$ series, the endosteal surface of the cortex, which bordered on the fixator, had signs of pronounced rearrangement. The marginal parts of the cortex had uneven contours in the form of patterns (Fig. 7), which are a reflection of the reaming of the cerebral canal with the introduction of the fixator and the activity of osteoclasts. Between the removed fixator and a bone there is a connecting fabric in which ter- ritories without cells, and in places of a site with the increased density of blood vessels are noted. Bone trabeculae formed a fine-loop mesh. This led to an increase in the width of the diaphysis. In places, the compact bone had almost a structure similar to spongy bone (due to a significant expansion of vascular channels) with the formation of large resorption spaces filled with red marrow.

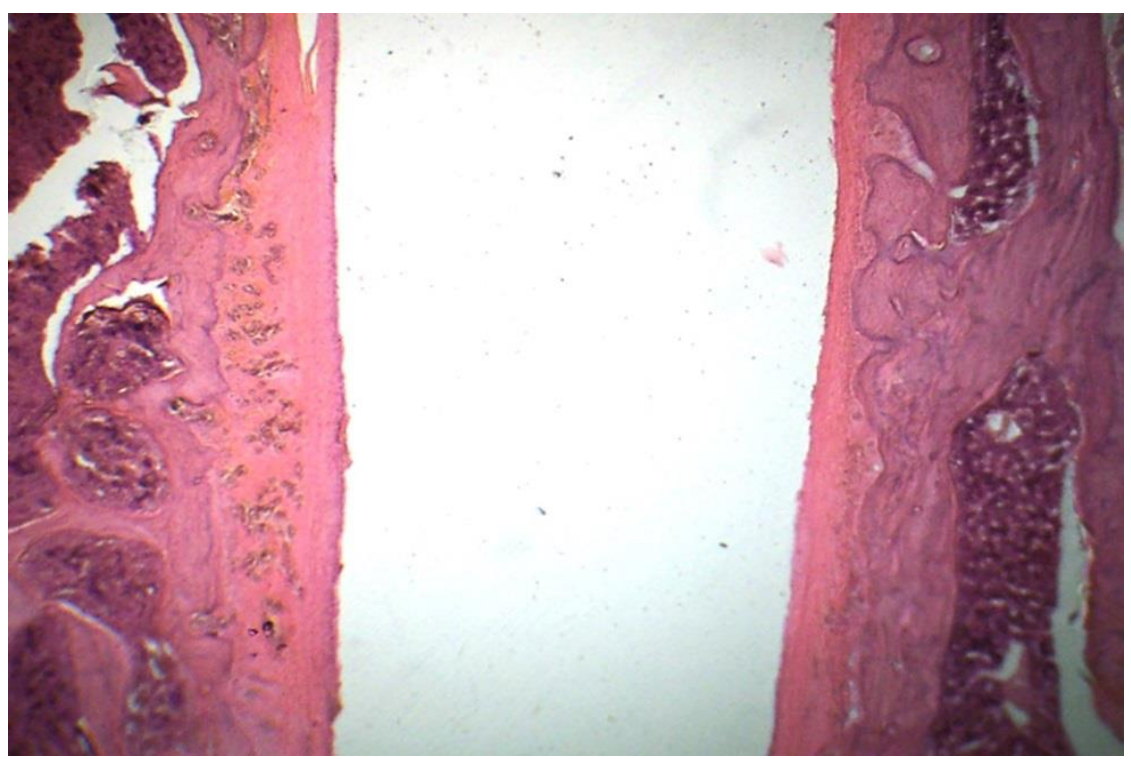

Fig. 7. A fragment of the femur with a significant rearrangement of the cortex. Large resorption lacunae on the endosteal surface of the cortex. Layers of connective tissue between the cortex and the fixator. 1 series, $90^{\text {th }}$ day. Haematoxylin and eosin, $\times 250$

Bone regeneration was observed in only three animals out of seven, but complete reorganization of the bone regenerate, which would correspond to the structure of the maternal cortex, does not occur. In most animals, the regenerate was represented by both bone tissue and chondroid, in some cases, with foci of ossification.

\section{Discussion of research results}

It is known that fractures form three types of regenerates - periosteal, intermedial and endosteal $[13,14]$. As a result of our study, it was found that regeneration under conditions of intramedullary osteosynthesis occurs during the formation of two types of regenerates - periosteal and intermedial. In this regard, a comparative study of the course of regeneration, namely in the periosteal and intermedial areas of the cortex.

It is established that bone fusion is more active when using an intramedullary fixator without reaming the bone marrow canal. This is confirmed by the appearance of bone tissue in the intermedial fracture zone in animals of this series on the $14^{\text {th }}$ day, in contrast to the first series, where bone tissue in the regenerate was recorded only on the $28^{\text {th }}$ day, and the vast majority of animals on the $90^{\text {th }}$ day with bone structure of intermedial regenerate. This may be due to the fact that the introduction of an intramedullary fixator without reaming the canal helps to preserve areas of the bone marrow that contains polypotent stromal cells, which are an additional component to increase the osteoblastic pool of cells on the endosteal surface and in the intermedial regenerate.
Comparing the morphological pictures of the intermedial regenerate on the $28^{\text {th }}$ day, it was found that the area of bone tissue in it was 2.6 times larger than in the first series of the experiment.

A study of the formation of periosteal regenerate as part of the fusion of bone fragments was also performed. It is known that the periosteal regenerate acts as a "provisional" structure. It is established that the restructuring of the periosteal regenerate occurs at an earlier date in animals with regeneration in the conditions of introduction of the fixator into the bone marrow canal without its reaming. This is due to the fact that the animals of this series form a stronger intramedullary regenerate. It is known that in conditions of partial or complete absence of endosteal regenerate, in the early stages of regeneration, the formation of a more powerful periosteal regenerate was recorded [14], which took place in studies in a series of experiments with bone marrow reaming and intramedullary fixation.

Important in the performance of intramedullary osteosynthesis is the study of the structural organization of bone fragments. It is established that reaming of the bone marrow canal reduces the manifestations of reparative potentials in the endosteal area and leads to activation of the process of restructuring the cortex not only in the endosteal part (inner general plates), but also in the central areas - the osteonic layer of the cortex. Thus, under the action of reaming, there is an activation of osteoclastic resorption, which is accompanied by the appearance of resorption-type cavities on the endosteal sur- 
face of the cortex. This leads to the formation of large resorption cavities in the areas of the inner general plates and the osteonic layer of the cortex, usurpation of the endosteal part of the cortex, accompanied by its thinning. The formation of resorption cavities in the cortex can be considered as a compensatory reaction of the bone under difficult conditions, which is affected not only by traumatic injury (simulated fracture), but also by reaming of the bone marrow canal and the action of a metal retainer.

A similar direction of the process of compensatory remodelling of bone tissue took place when the fixator was inserted into the bone marrow canal without reaming, but the manifestations of disorders in the cortex were much smaller. Yes, we did not observe the formation of endosteal regenerate. Fracture healing actually occurred due to the development of periosteal regenerate, which was represented by a network of bone trabeculae. They formed on the surface of the periosteum structures similar to "boxes". However, as shown in our studies, and based on the results of studies by other specialists, the formation of periosteal regenerate is closely dependent on the formation of endosteal regenerate [14].

To date, the role of the yellow bone marrow in reparative osteogenesis has not been fully elucidated, as the latter is subject to total damage during bone marrow canal reaming. In our opinion, the yellow bone marrow is a powerful depot of stromal stem cells of mesenchymal origin, and adipocytes of the yellow bone marrow are a source of osteogenic stem stromal cells.

Study limitations. The study was limited to the criteria for inclusion of animals in the experiment (56 white adult laboratory rats aged 6 months, live weight 280-310 g WAG line), simulated injury - diaphyseal fracture of the femur and subsequent surgery - intramedullary osteosynthesis with and without reaming of the bone marrow canal.
Prospects for further research. Further quantitative studies of multipotent stromal stem cells localized in the yellow bone marrow and their role in the reparative osteogenesis of bone tissue are promising. It is likely that such studies will explain in more detail the decrease in the reparative capacity of the bone tissue of rats, the fixation of fragments of which was carried out with the reaming of the bone marrow canal. It is important to further study the impact of this surgical technology, primarily on reparative osteogenesis and the occurrence of possible reparative complications in the treatment of fractures of long bones of the extremities in humans.

\section{Conclusions}

1. Bone fusion in conditions of intramedullary osteosynthesis is more active when using intramedullary fixator without reaming of the cerebral canal, which is confirmed by the appearance of bone tissue in the intermedial fracture zone on the $14^{\text {th }}$ day, in contrast to animals with reaming of the cerebral canal, where the bone tissue in the regenerate was recorded only on the $28^{\text {th }}$ day, and the vast majority of animals on the $90^{\text {th }}$ day with the bone structure of the intermedial regenerate.

2. Reaming of the cerebral canal reduces the manifestations of reparative potentials in the endosteal area and leads to the activation of the process of restructuring the cortex of both the endosteal and its central part. Activation of osteoclastic resorption is noted, which is accompanied by the appearance of resorption cavities on the endosteal surface of the cortex and the formation of large resorption cavities and usurpation of the endosteal part of the cortex. The cortex takes the form of a cancellous bone.

\section{Conflict of interests}

The authors declare that they have no conflicts of interest.

\section{References}

1. Mansyrov, A. B., Lytovchenko, V., Garyachiy, Y., Lytovchenko, A. (2020). Bone-cerebral channel reaming in the treatment of limbs bone fractures. ScienceRise, 6 (71), 40-50. doi: http://doi.org/10.21303/2313-8416.2020.001559

2. Giannoudis, P. V., Snowden, S., Matthews, S. J., Smye, S. W., Smith, R. M. (2002). Temperature Rise During Reamed Tibial Nailing. Clinical Orthopaedics and Related Research, 395, 255-261. doi: http://doi.org/10.1097/00003086-200202000-00031

3. Rommens, P. M., Kuechle, R., Hofmann, A., Dietz, S.-O. (2018). Repositionstechniken in der Marknagelosteosynthese. Der Unfallchirurg, 122 (2), 95-102. doi: http://doi.org/10.1007/s00113-018-0560-1

4. Rosa, N., Marta, M., Vaz, M., Tavares, S. M. O., Simoes, R., Magalhães, F. D., Marques, A. T. (2019). Intramedullary nailing biomechanics: Evolution and challenges. Proceedings of the Institution of Mechanical Engineers, Part H: Journal of Engineering in Medicine, 233 (3), 295-308. doi: http://doi.org/10.1177/0954411919827044

5. Meeuwis, M. A., de Jongh, M. A. C., Roukema, J. A., van der Heijden, F. H. W. M., Verhofstad, M. H. J. (2015). Technical errors and complications in orthopaedic trauma surgery. Archives of Orthopaedic and Trauma Surgery, 136 (2), $185-193$. doi: http://doi.org/10.1007/s00402-015-2377-5

6. Buhl, C. A. (2019). 80 years of intramedullary nailing: New facts and information about a milestone in osteosynthesis. Der Unfallchirurg, 122 (2), 127-133. doi: http://doi.org/10.1007/s00113-018-0598-0

7. Li, A.-B., Zhang, W.-J., Guo, W.-J., Wang, X.-H., Jin, H.-M., Zhao, Y.-M. (2016). Reamed versus unreamed intramedullary nailing for the treatment of femoral fractures. Medicine, 95 (29), e4248. doi: http://doi.org/10.1097/md.0000000000004248

8. Ocalan, E., Ustun, C. C., Aktuglu, K. (2017). Reamed vs. Unreamed Intramedullary Nailing of Femoral Fractures in the Elderly. Trauma Acute Care, 4 (2 (48)), 1-7.

9. Metsemakers, W.-J., Roels, N., Belmans, A., Reynders, P., Nijs, S. (2015). Risk factors for nonunion after intramedullary nailing of femoral shaft fractures: Remaining controversies. Injury, 46 (8), 1601-1607. doi: http://doi.org/10.1016/ j.injury.2015.05.007

10. Shao, Y., Zou, H., Chen, S., Shan, J. (2014). Meta-analysis of reamed versus unreamed intramedullary nailing for open tibial fractures. Journal of Orthopaedic Surgery and Research, 9 (1). doi: http://doi.org/10.1186/s13018-014-0074-7

11. Glatt, V., Evans, C. H., Tetsworth, K. (2017). A Concert between Biology and Biomechanics: The Influence of the Mechanical Environment on Bone Healing. Frontiers in Physiology, 7. doi: http://doi.org/10.3389/fphys.2016.00678 
12. Mansyrov, A. B., Lytovchenko, V. O., Gariachyi, Y. V. (2020). Complications of Intramedullary Blocking Osteosynthesis of Bones of Limbs and Ways to Prevent Them. Visnyk Ortopedii Travmatologii Protezuvannia, 2 (105), 35-42. doi: http://doi.org/10.37647/0132-2486-2020-105-2-35-42

13. Popsuyshapka, O., Litvishko, V., Ashukina, N. (2015). Clinical and morphological stages of bone fragments fusion. Orthopaedics, traumatology and prosthetics, 1, 12-20. doi: http://doi.org/10.15674/0030-59872015112-20

14. Stupina, T. A., Emanov, A. A., Antonov, N. I. (2016). Bone union and structural changes in the articular cartilage of the knee joint after immediate and delayed antegrade locked intramedullary nailing of femoral shaft fractures. Experimental findings. Genij Ortopedii, 4, 76-80. doi: http://doi.org/10.18019/1028-4427-2016-4-76-80

15. Lavrischeva, G. I., Onoprienko, G. A. (1996). Morfologicheskie i klinicheskie aspekty reparativnoi regeneratsii opornykh organov i tkanei. Moscow: Meditsina, 208.

Received date 08.12.2020

Accepted date 04.01.2021

Published date 31.03.2021

Asif Mansyrov, Postgraduate Student, Department of Emergency and Urgent Health Care, Orthopedics and Traumatology, Kharkiv National Medical University, Nauky ave., 4, Kharkiv, Ukraine, 61022

E-mail: asifchyk@gmail.com

Viktor Lytovchenko, MD, Professor, Department of Emergency and Urgent Health Care, Orthopedics and Traumatology, Kharkiv National Medical University, Nauky ave., 4, Kharkiv, Ukraine, 61022

E-mail: lyt_v@ukr.net

Yevgeniy Garyachiy, PhD, Assistant, Department of Emergency and Urgent Health Care, Orthopedics and Traumatology, Kharkiv National Medical University, Nauky ave., 4, Kharkiv, Ukraine, 61022

E-mail: garja4ij@ukr.net

Andriy Lytovchenko, PhD, Assistant, Department of Emergency and Urgent Health Care, Orthopedics and Traumatology, Kharkiv National Medical University, Nauky ave., 4, Kharkiv, Ukraine, 61022

E-mail: lyt_v@ukr.net

Olena Miroshnichenko, PhD, Professor, Department of Histology, Cytology and Embryology, Kharkiv National Medical University, Nauky ave., 4, Kharkiv, Ukraine, 61022

E-mail: o.v.miroshnichenko@ukr.net 